\title{
Does knowledge based psychological ownership matter? Transformational leadership and knowledge hiding: A proposed framework
}

\author{
Sahnun Ladan \\ Norani Binti Nordin \\ Belal, H. M
}

School of Technology Management and Logistics, Universiti Utara Malaysia, Malaysia

\begin{abstract}
Keywords
Transformational leadership, knowledge based psychological ownership, knowledge hiding
\end{abstract}

\begin{abstract}
The prevalent and negative impact of knowledge hiding behaviour among employees has called the attention of both practitioners and researchers to begin investigations on its causes, and other factors that influence it on both the targets and perpetrators. Some of the possible suggested antecedents of knowledge hiding studied include trust, job characteristic, organisational culture, and workplace environment. Despite these studies, few have attempted to investigate the influence of leadership, particularly, transformational leadership on knowledge hiding. Previous studies also indicated conflicting results, and the mechanisms through which transformational leadership influences knowledge hiding are not adequately addressed. Therefore, mediator variable is suggested. Hence, this paper proposes knowledge psychological ownership as a potential mediator on the relationship between transformational leadership and knowledge hiding behaviour of an employee in the organization. We hereby argue that transformational leadership through knowledge psychological ownership will influence employees to refrain from the knowledge hiding behaviour that may negatively affect the organisation and encourage knowledge sharing to improve the performance of the organization.
\end{abstract}

Corresponding author: Sahnun Ladan

Email address for the corresponding author: sahnunl@yahoo.com

First submission received: 28th January 2017

Revised submission received: 21st February 2017

Accepted: 8th April 2017

\subsection{Introduction}

Research on knowledge management has received more attention from the scholars and practitioners. This is as a result of its positive impact on organizational performance (Alegre, Sengupta, \& Lapiedra, 2011; Emadzade, Mashayekhi, \& Abdar, 2012). It encourages creativity and innovations in the organization (Nonaka \& Lewin, 2010; Saulais \& Ermine, 2012; Sigala \& Chalkiti, 2015). Described as "the process of capturing, developing, sharing, and effectively using organizational knowledge" (Davenport, 1994), knowledge management contributes to the achievement of organizational competitive advantage (Meihami \& Meihami, 2014; Rahimli, 2012). However, emphases were mostly on the influence of knowledge sharing on organizational progress, performance and gain competitive advantages (Baytok, Kurt, \& Zorlu, 2014; Du, Ai, \& Ren, 2007; Hsu, 2008).

Despite its prevalence and negative impacts on the organization (Connelly, Zweig, Webster, \& Trougakos, 2012; Connelly \& Zweig, 2015; Peng, 2013), little attention has been given to the employee's knowledge hiding behaviour in organization. In particular, there is little regard to the knowledge hiding behaviours of academicians' in universities. In a survey conducted in United States of America (USA), it was reported that 76 percent of respondents agreed they have once 
engaged in knowledge hiding (Connelly et al., 2012). In addition, a survey conducted in China (Peng, 2012) shows that 46 percent of respondents reported they once involved in knowledge hiding behaviour in their work settings.

Several reasons have been suggested to why employees hide knowledge, to date some of the extant empirical factors on the antecedents of knowledge hiding studied mostly focused on distrust, knowledge complexity, task-relatedness, and knowledge sharing climate (Connelly et al., 2012, Webster et al., 2008), organizational culture (Webster et al., 2008), territoriality and organizational ownership (Peng, 2013), work environment and personality (Demirkasimoglu, 2015; Nerstad, 2014; Webster et al., 2008), goal interdependent (Lam \& Bavik, 2015), competition and time (Connelly, Ford, Gallupe, Turel, \& Zweig, 2009), knowledge complexity (Pan \& Zhang, 2014) and also as a result of laziness, pro-social and instrumental (Webster et al., 2008). However, less attention has been given to the influence of leadership on employee knowledge hiding behaviour, particularly, transformational leadership. Transformational leadership is defined as a process where "leaders and followers help each other to advance to a higher level of morale and motivation"(Burns, 1978). Thus, the purpose of this paper is to build a theoretical framework on the mediation effect of knowledge based psychological ownership on transformational leadership and knowledge hiding relationship. Therefore, identifying follower knowledge based psychological ownership as a mediating mechanism may improve systematic understanding of the impact of transformational leadership on followers knowledge hiding behaviour, and help management practitioners in developing and adopt a useful leadership interventions to improve organizational performance.

\subsection{Literature Review}

\subsection{Knowledge hiding}

According to Davenport and Prusak (1998, p. 5), Knowledge is defined as "a fluid mix of framed experience, values, contextual information, and expert insights that provide a framework for evaluating and incorporating new experiences and information". Knowledge hiding is defined as the "withholding or concealing of relevant information or knowledge, ideas, and know-how requested by a co-worker at workplace" (Connelly et al., 2012). Knowledge hiding also implies that an individual will give less information in contributing to organizational knowledge (Lam \& Bavik, 2015; Lin \& Huang, 2010). Furthermore, knowledge hiding may cause harm to the collaborations in an organization, developing new ideas, or policies implementation and procedures. It is also usually a negative perspective on an individual's knowledge contribution in most work settings. Accordingly, knowledge hiding may be positive in some cases, for example, protecting the organization private right (Connelly et al., 2012; Peng, 2013). Knowledge hiding is not considered to be opposite to knowledge sharing, but they are related and distinct constructs (Connelly et al., 2012; Connelly \& Zweig, 2015; Demirkasimoglu, 2015; Peng, 2013).

According to Connelly, Zweig, Webster, and Trougakos, (2012), knowledge hiding comprises of three elements: rationalized hiding, evasive hiding, and playing dumb. Evasive hiding is a situation where knowledge hider provides a misleading or incorrect information and promise to complete the answer which he/she is not intended to provide. Rationalized hiding is a situation where the knowledge hider provides justification for not sharing the knowledge requested by the coworker and transferring the blame to the third party. For example, the information is a classified and not allowed for the third party. Another dimension of knowledge hiding is playing dumb; the hider of the knowledge "pretends to be ignorant of the relevant knowledge requested by a subordinate; for example, "I don't know about the knowledge".

\subsection{Transformational Leadership}

Transformational leadership is defined as a process by which leaders motivate their employees to outperform an initially expected level and to transcend followers' individual interests in order to accomplish a collective goal (Bass 1985; Howell \& Avolio 1993). Transformational 
leadership is also defined as a process in which "leaders and followers raise one another to higher levels of morality and motivation (Burns, 1978 p. 20). Transformational leadership also refers to a leader moving the follower beyond immediate self-interests through idealized influence, inspiration, intellectual stimulation, or individualized consideration. Thus, the ability to develop the needs of the followers is the main focus of transformational leadership in organization. Transformational leaders help followers to consider the goal and values of the organization above their own (Hyypi, \& Parjanen, 2013; Shamir, House, \& Arthur, 1993).

\subsection{Theoretical Framework}

\subsection{Transformational Leadership and Knowledge Hiding}

Studies show that leadership has an influence on individual employee behaviour and attitude (Bass, 1990; Bass, 2006; Olson \& Nelson, 2006; Park et al., 2013; Shamir et al.,1993).Transformational Leadership also influence followers to be creative and innovative that improved the performance of organization (Bryant, 2003). Additionally, a transformational leader is defined as "leaders and followers help each other to advance to a higher level of morale and motivation (Burns, 1978)". Transformational leaders are those leaders that exhibit respectful, trustworthiness and behaviour that are ethical, increase inspiration and maturity, provide intellectuality, pay attention to their needs for achievement and growth. They also encourage their followers to assume more responsibility that may develop them to leadership (Avolio et al., 1999; Bass, 2006).

Regarding transformational leadership and knowledge hiding, empirical studies for the relationship between transformational leadership and knowledge hiding is inadequate. However, given the limited number of studies linking transformational leadership and knowledge hiding, review of literatures revealed positive impact of transformational leaders for encouraging knowledge sharing among the followers within the organization which improve performance and creativity (Akpotu \& Tamunosiki-Amadi, 2013; Bryant, 2003; Lin \& Hsiao, 2014; Mushtaq \& Bokhari, 2011).

In contrast, knowledge hiding encouraged a lack of creativity and innovation, and also has a negative impact on the performance of the organization, and interpersonal relationship (Connelly \& Zweig, 2015; Nerstad, 2014). It can then be argue that transformational leader will not encourage followers to engage in any dysfunctional behaviour that may be detrimental to the organization. Given the positive relationship between transformational leadership and knowledge sharing, it is logical that transformational leadership may play a vital role in minimizing the tendency of the employee to hide knowledge in the workplace. We proposed that:

H1: An increase in transformational leadership will reduce knowledge hiding behaviour.

\subsection{Transformational Leadership and Knowledge based Psychological Ownership}

A transformational leader is defined as "leaders and followers help each other to advance to a higher level of morale and motivation, (Burns, 1978)". There are limited empirical literature that relates transformational leadership and knowledge psychological ownership. However, extant studies show that leadership has an influence on individual employee behaviour and attitude (Bass, 1990; Olson \& Nelson, 2006; Park et al., 2013; Shamir et al., 1993). Liu, (2012) defined knowledge psychological ownership as a "mindset in which employees perceive that a certain knowledge or information belongs to them".

Transformational leaders exhibit respectful, trustworthy, and behaviours that are ethical, increase productivity and motivation, provide individual stimuli, and pay attention towards their followers needs in terms of achievement and growth (Avolio et al., 2004; Bass, 2006; Snjezana Kovjanic, Schuh, \& Jonas, 2013; López-domínguez et al., 2013). Knowledge psychological ownership makes an individual to psychologically keep some particular knowledge and regard it as the extension of personality and then attain the senses of protection, efficacy and esteem from it. Similarly, where an employee is being rewarded, either physical or mentally, based on his special 
knowledge, there would be fear or feeling that by sharing the knowledge, he will lose his competitive advantage, self esteem, and security (Li et al., 2015; Peng, 2013; Xinyan \& Xin, 1986). The study of Li et al. (2015) of 293 employees in China based on structural equation revealed that knowledge based psychological ownership has a negative influence on both affective commitment and knowledge sharing as well. Furthermore, Xinyan and Xin, (1986) investigate the moderating effects of organizational justice on knowledge psychological ownership and knowledge hiding behaviour; the research revealed that knowledge psychological ownership could constrain knowledge sharing behaviour. Peng (2013), a survey of 190 employees reported positive on the relationship between knowledge psychological ownership and knowledge hiding. Previous studies also revealed that transformational leadership is positively related to knowledge sharing (Bryant, 2003; Lin \& Hsiao, 2014), job commitment and job satisfaction (Avolio et al., 2004; Griffiths, 2004), creativity and innovation (Bryant, 2003; Noruzy et al., 2013; Qu et al., 2015).

Based on transformational leadership theory (Bass, 1995; Burns, 1978; Shamir et al., 1993), transformational leadership is the process of stimulating individual intellectually through personal attention, coaching, and mentoring in facilitating problem solving and rational thinking. Transformational leadership is leadership approaches that bring change in individuals and the systems, which also has an influence on individual employee behaviour and attitude (Bass, 1990; Olson \& Nelson, 2006; Park et al., 2013; Shamir et al., 1993). In line with above theoretical and empirical studies, the present study proposed that;

H2: An increase in transformational leadership will reduce knowledge based psychological ownership behaviour.

\subsection{Knowledge Based Psychological Ownership as a Mediator}

Liu, (2012) defined knowledge psychological ownership as a "mindset in which employees perceive that a certain knowledge or information belongs to them". Although psychological ownership has been frequently identified as being one of the factors which influence individual behaviour and attitude, there are limited empirical studies focusing on knowledge hiding (Connelly et al., 2012; Peng, 2013).

Furthermore, knowledge psychological ownership shows the level at which an individual employee feelings of possession or ownership of a particular knowledge. This may be as a result of their investment of much efforts or time/money in acquiring the knowledge. Moreover, employees have control over the knowledge they have created, acquired or familiar with in their daily routine. The control over the knowledge may serve as a competitive advantage to the knowledge holder in bargaining power upon their organization for rewards to exit from the organization (Peng, 2013). Further, once employees have the feeling of knowledge psychological ownership, knowledge sharing in the organization would be impeded. In so doing, an individual with knowledge psychological ownership would refuse to share core knowledge among others in order to avoid threat or the decline of possession to the knowledge, demands of security, competitive advantage, efficacy and needs, and self-esteem; thus, instinctively rejecting knowledge sharing (Peng, 2013; Van Dyne \& Pierce, 2004; Xinyan \& Xin, 1986). In addition, an employee with strong knowledge psychological ownership has a tendency to engage in dysfunctional behaviours in order to keep the ownership of the target (Peng, 2013). Experience for personal loss, stress and frustration may discourage knowledge sharing behaviour. Based on these facts, it can be argued that individual employee with high knowledge psychological ownership is likely to conceal knowledge unlike employee with low knowledge psychological ownership.

Previous studies have examined the mediating role of knowledge based psychological ownership on the relationship between affective commitment and both common and key knowledge sharing. The study revealed that knowledge psychological ownership mediates the relationship between the affective commitment and knowledge sharing behaviour ( $\mathrm{Li}$, Yuan, Ning, \& Li-Ying, 
2015). The theory of psychological ownership posits that psychological ownership is said to be state in which individual feels as though the target of ownership or a piece of that target is theirs" (Pierce et al., 2001). This indicate that, considering oneself as part of ownership or feeling ownership, that will make individual to increase his/her effort towards organizational progress. In addition, despite the fact studies asserts that knowledge based psychological owners protect their interest because of their unique knowledge (Peng, 2013), a leader can influence his followers behaviour and attitudes, changing their perceptions and self concept towards positive behaviours. We therefore, propose that:

H3: Knowledge base psychological ownership will mediate transformational leadership and knowledge hiding relationship.

Considering the above empirical literature, this paper proposes a research framework illustrating the mediating role of knowledge based psychological ownership on transformational leadership and knowledge hiding relationship as depicted in figure 1 . The paper indicates that the extent to which transformational leadership influences knowledge hiding behaviour depends on the level of knowledge based psychological ownership of the employee. Thus, an employee with a high level of knowledge psychological ownership will likely engage in knowledge hiding behaviour unlike individual with low knowledge psychological ownership. We also argued that transformational leadership style can enhance knowledge psychological ownership of the followers through inspiration by presenting an appealing future and set achievable task related goals and expectations and how to achieve this vision.

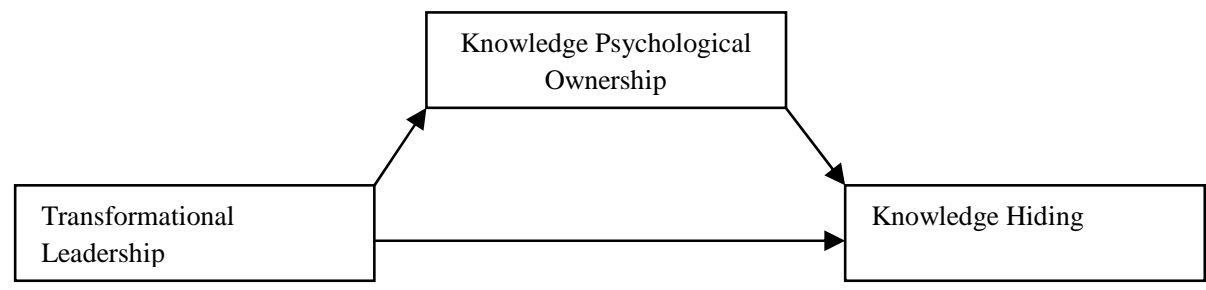

Figure 1: Conceptual Model of the Influence of transformational leadership on knowledge hiding: the role of knowledge based psychological ownership.

\subsection{Conclusion}

Based on the theoretical and empirical studies discussed above, this paper proposes a theoretical framework on the mediating role of knowledge based psychological ownership between transformational leadership and knowledge hiding behaviour as depicted in figure 1 above. If the proposed model is validated, the result will contribute to knowledge management literature and management of knowledge hiding in particular if considered a dysfunctional behaviour in organizations. Furthermore, the theoretical frame work will give an insight into the role of transformational leadership in knowledge hiding behaviour. The study will also contribute by identifying knowledge psychological ownership as a mediating mechanism that can ensure systematic understanding of effect of transformational leadership on follower knowledge hiding behaviour, and also assist management practitioners in developing and use efficient and effective leadership that improves employees' performance

However, this paper is limited to transformational leadership and other leadership styles were not considered. Future study should consider other leadership styles, such as; servant leadership, transactional leadership to mention a few. Future study should also investigate the influence of organizational control, rewards, and organizational culture. The mechanisms (mediator or moderators) variables such as self efficacy, organizational commitment, are also yet to be examined. 


\section{Reference}

Akpotu, C., \& Tamunosiki-Amadi, J. (2013). Transformational Leadership and Knowledge Sharing in ICT Based Organizations in Nigeria. International Journal of Business and Social Science, 4(12), 100-107.

Alegre, J., Sengupta, K., \& Lapiedra, R. (2011). Knowledge management and innovation performance in a high-tech SMEs industry. International Small Business Journal, 31(4), 454-470.

Argote, L., \& Ingram, P. (2000). Knowledge Transfer: A Basis for Competitive Advantage in Firms. Organizational Behavior and Human Decision Processes, 82(1), 150-169.

Avolio, B. J., Bass, B. M., \& Jung, D. I. (1999). Re-examining the components of transformational and transactional leadership using the Multifactor Leadership Questionnaire, 441-462.

Avolio, B. J., Zhu, W., \& Koh, W. (2004). Transformational leadership and organizational commitment : mediating role of psychological empowerment and moderating role of structural distance, 968(May), 951-968.

Bass, B. M. (1990). From Transactional to Iransformational Leadership : Learning to Share the Vision. Organizational Dynamics, 18(3), 19-32.

Baytok, A., Kurt, M., \& Zorlu, Ö. (2014). The Role of Transformational Leader on Knowledge Sharing Practices : A Study about International Hotel Chains, 6(7), 46-61.

Bernard M. Bass, R. E. R. (2006). Transformational leadership (2nd ed.). Mahwah, N. J.

Bryant, S. E. (2003). The Role of Transformational and Transactional Leadership in Creating, Sharing and Exploiting Organizational Knowledge. Journal of Leadership Eamp; Organizational Studies, 9(4), 32-44.

Burns, J. M. (1978). Leadership. In Leadership (pp. 66-75).

Connelly, C. E., Ford, D. P., Gallupe, B., Turel, O., \& Zweig, D. (2009). The effects of competition and time constraints on knowledge transfer: Exploratory findings from two experiments. Proceedings of the 42nd Annual Hawaii International Conference on System Sciences, HICSS, 1-10.

Connelly, C. E., \& Zweig, D. (2015a). How perpetrators and targets construe knowledge hiding in organizations. European Journal of Work and Organizational Psychology, 24(3), 479-489.

Connelly, C. E., \& Zweig, D. (2015b). How perpetrators and targets construe knowledge hiding in organizations. European Journal of Work and Organizational Psychology, 24(3), 479-489.

Connelly, C. E., Zweig, D., Webster, J., \& Trougakos, J. P. (n.d.). Knowledge hiding in organizations.

Connelly, C. E., Zweig, D., Webster, J., \& Trougakos, J. P. (2012). Knowledge hiding in organizations, (88), 64-88.

Davenport, B. T. H., \& Prusak, L. (1998). Working Knowledge: How Organizations Manage What They Know. Knowledge Creation Diffusion Utilization, 309.

Davenport, T. H. (1994). Saving IT's Soul: Human Centered Information Management. Harvard Business Review, 72(2), 119-131.

Demirkasimoglu, N. (2015). Knowledge Hiding in Academia: Is Personality a Key Factor? International Journal of Higher Education, 5(1).

Du, R., Ai, S., \& Ren, Y. (2007). Relationship between knowledge sharing and performance: A survey in Xi'an, China. Expert Systems with Applications, 32(1), 38-46.

Emadzade, M. K., Mashayekhi, B., \& Abdar, E. (2012). Knowledge management capabilities and organizational performance. Interdisciplinary Journal of Contemporary Research in Business, 3(11), 781-790.

Gurteen, D. (2007). Knowledge , Creativity and Innovation. Journal of Knowledge Management, Vol. 2(Iss: 1), pp.5 - 13.

Hsu, I. C. (2008). Knowledge sharing practices as a facilitating factor for improving organizational performance through human capital: A preliminary test. Expert Systems with Applications, 35(3), 1316-1326.

Hyypi??, M., \& Parjanen, S. (2013). Boosting creativity with transformational leadership in fuzzy 
front-end innovation processes. Interdisciplinary Journal of Information, Knowledge, and Management, 8, 21-41.

Kang, S.-W. (2014). Knowledge withholding: Psychological hindrance to the innovation diffusion within an organisation. Knowledge Management Research \& Practice, (April), 1-6.

Kovjanic, S., Schuh, S. C., \& Jonas, K. (2013). Transformational leadership and performance: An experimental investigation of the mediating effects of basic needs satisfaction and work engagement. Journal of Occupational \& Organizational Psychology, 86(4), 543-555.

Lam, Y., \& Bavik, F. (2015). Effects of goal interdependence on help-seeking through knowledge sharing and knowledge hiding: the moderating roles of reciprocity beliefs Terms of Use The copyright of this thesis is owned by its.

Li, J., Yuan, L., Ning, L., \& Li-ying, J. (2015). Knowledge sharing and affective commitment: the mediating role of psychological ownership.

Lin, R. S., \& Hsiao, J. (2014). The Relationships between Transformational Leadership , Knowledge Sharing , Trust and Organizational Citizenship Behavior, 5(3), 3-6.

Lin, T. C., \& Huang, C. C. (2010). Withholding effort in knowledge contribution: The role of social exchange and social cognitive on project teams. Information and Management, 47(3), 188-196.

López-domínguez, M., Enache, M., Sallan, J. M., \& Simo, P. (2013). Transformational leadership as an antecedent of change-oriented organizational citizenship behavior is. Journal of Business Research, 66(10), 2147-2152.

Meihami, B., \& Meihami, H. (2014). Knowledge Management a way to gain a competitive advantage in firms (evidence of manufacturing companies). International Letters of Social and Humanistic ..., 3, 80-91.

Mushtaq, R., \& Bokhari, R. H. (2011). Knowledge sharing: organizational culture and transformational leadership. Journal of Knowledge Management Practice.

Nerstad, C. G. L. (2014). What Goes Around Comes Around: Knowledge Hiding, Perceived Motivational Climate, and Creativity, 57(1), 172-192.

Nonaka, I., \& Lewin, A. Y. (2010). Dynamic Theory Knowledge of Organizational Creation, 5(1), $14-$ 37.

Olson, B. J., \& Nelson, D. L. (2006). Managing aggression in organizations : what leaders must know. doi:10.1108/01437730610677981

Pan, W., \& Zhang, Q. (2014). A Study on Motivations of Graduate Students ' Knowledge Hiding Based on Wuli-Shili-Renli System Approach *, (Icemss), 117-120.

Park, C. H., Song, J. H., Yoon, S. W., \& Kim, J. (2013). Human Resource Development International A missing link: psychological ownership as a mediator between transformational leadership and organizational citizenship behaviour, (December 2014), 37-41.

Peng, H. (2013). Why and when do people hide knowledge? Journal of Knowledge Management, 17(3), 398-415.

Qu, R., Janssen, O., Shi, K. (2015). Transformational leadership and follower creativity: The mediating role of follower relational identification and the moderating role of leader creativity expectations. Leadership Quaterly, 16(2), 286-299.

Rahimli, A. (2012). Knowledge Management and Competitive Advantage. Information and Knowledge Management, 2(7), 37-43.

Saulais, P., \& Ermine, J.-L. (2012). Creativity and knowledge management. VINE: The Journal of Information \& Knowledge Management Systems, 42(3/4), 416-438.

Shamir, B., House, R. J., \& Arthur, M. B. (1993). The Motivational Effects of Charismatic Leadership: A Self-Concept Based Theory The Motivational Effects of Charismatic Leadership: A SelfConcept Based Theory*. Source: Organization Science Organization Science, 4(4), 577-594.

Sigala, M., \& Chalkiti, K. (2015). Knowledge management, social media and employee creativity. International Journal of Hospitality Management, 45, 44-58. 
Webster, J., Brown, G., Zweig, D., Connelly, C. E., Brodt, S., \& Sitkin, S. (2008). Beyond knowledge sharing: Withholding knowledge at work. Research in Personnel and Human Resources Management, 27(08), 1-37.

Xinyan, Z., Xin, Z. (1986). Moderating effects of organizational justice to knowledge-based psychological ownership and knowledge sharing. 8th International Conference on Innovation $\mathcal{E}$ Management, 875-879 